\title{
Colonización alemana en la frontera entre Colombia y Panamá (1886-1941)
}

German colonization on the border between Colombia and Panama (1886-1941)

Cómo citar este

artículo en APA:

Horta, C. M. (2021).

Colonización alemana

en la frontera entre

Colombia y Panamá

(1886-1941). Analecta

Política, 11(20),

64-85. doi: https://doi. org/10.18566/apolit.

v11n20.a04

Fecha de recepción: 09.06.2020

Fecha de aceptación: 19.03.2021

\section{CAROLINA MARÍA HORTA GAVIRIA}

Doctora en Historia Universidad Pontificia Bolivariana, Colombia Grupo de Investigación en Estudios Políticos Correo electrónico: carolina.horta@upb.edu.co 


\section{Resumen}

Este artículo analiza la colonización alemana en la frontera entre Colombia y Panamá para el periodo 1886-1941. Siguiendo el método hermenéutico, se interpretaron diversas fuentes impresas y manuscritas que datan de dicho periodo producidas por el Gobierno de Colombia: Ministerio de Relaciones Exteriores, Ministerio de Guerra, Ministerio de Gobierno, Ministerio de Negocios Extranjeros, Ministerio de Industrias, Ministerio de Agricultura y Comercio, Ministerio de Hacienda. Se encontró que, para el periodo de estudio, el Estado colombiano promovió la colonización alemana, y así se configuró una amenaza para el coloso del Norte, los Estados Unidos. La economía mundial incentivó la rivalidad imperial y la colonización en la frontera entre Colombia y Panamá.

Palabras clave: colonización, frontera, Alemania, Colombia, Panamá

\section{Abstract}

This article analyzes the German colonization process on the border between Colombia and Panama for the period 1886-1941. Following the hermeneutical method, various printed and handwritten sources dating from that period produced by various Government ministries were interpreted: the Ministry of Foreign Relations, the Ministry of War, the Ministry of Government, the Ministry of Foreign Business, the Ministry of Industries, the Ministry of Agriculture and Commerce, the Ministry of Finance. It was found that, for the study period, the Colombian State promoted German colonization, whic became a threat for the so-called colossus of the North, or the United States. The world economy fueled imperial rivalry and colonization on the border between Colombia and Panama.

Keywords: colonization, border, Germany, Colombia, Panama. 


\section{Introducción}

Durante los primeros treinta años del siglo XX en la frontera entre Colombia y Panamá avanzaron fuerzas productivas capitalistas que se lanzaron hacia la extracción de los recursos naturales (frutas, maderas, caucho, petróleo, minas de oro). Durante el siglo XIX un canal interoceánico en este territorio era de interés público internacional. Los colombianos, muchos de ellos afrodescendientes e indígenas, participaron en el desarrollo de la agricultura, sector dinámico del mercado, pero el lugar de la participación que se les dio fue marginal, sin la más mínima posibilidad de convertirse en propietarios de la tierra. En este mismo siglo, las naciones europeas en proceso de industrialización entraron en una rivalidad mutua creciente e incrementaron más que nunca la expansión de su poderío a costa de los pueblos menos desarrollados (Elias, 2012, p. 45).

El Urabá colombiano, espacio fronterizo entre Colombia y Panamá, es una producción territorial resultado de la pugna por un canal interoceánico. Urabá pertenece a una región transnacional localizada al sureste de América del Norte, al este de América Central y al norte de América del Sur. Los flujos migratorios en este territorio se han realizado durante siglos siguiendo el curso del río Atrato o Darién que desemboca en el mar Caribe.

A partir de 1826, con el Congreso Anfictiónico de Panamá, se promovieron las gestiones conducentes a que los gobiernos de Gran Bretaña, Francia, los Estados Unidos y Holanda enviasen colonos a construir un canal interoceánico en Panamá, Atrato o Darién. En 1903, con la separación de Panamá y las negociaciones del canal interoceánico con los Estados Unidos, la migración alemana fue deseada para la Regeneración, ${ }^{1}$ y aunque fue exitosa, duró poco, terminó tras la Primera y Segunda Guerra Mundial. El Gobierno colombiano en 1930 realizó una transición de un Gobierno conservador a uno liberal, lo que implicó también un cambio de la mirada diplomática desde Alemania a los Estados Unidos.

El objetivo de este artículo es comprender el proceso de colonización de la frontera entre Colombia y Panamá, territorio conocido en el interior del país

1 La Regeneración es un periodo de la historia política colombiana que va de 1886 a 1930. En este periodo, el Partido Conservador obtuvo el gobierno del país, tras lo cual restringió las libertades de participación y representación a los miembros del Partido Liberal. En 1886, se aprobó una constitución que eliminó el federalismo y dio poderes extraordinarios al presidente de la república como el nombramiento de gobernadores, la declaración del estado de sitio y otras disposiciones con carácter de ley, se eliminaron los derechos del hombre y el ciudadano, se restringieron las libertades y se acogió la idea de una república autoritaria (Melo, 2020, p. 174). 
como Urabá, para el periodo 1886-1941, en el contexto de la Regeneración, la Hegemonía Conservadora y la transición hacia la Hegemonía Liberal de la República de Colombia.

El Estado colombiano llamaba a colonos de los imperios europeos para que se apropiaran de los territorios nacionales para convertirlos en colonias agrícolas que aumentaran la productividad del suelo y la rentabilidad del Estado, además de "mejorar la raza" y posibilitar el enclave de la civilización occidental europea. Elias (2012, p 130) señala que la civilización es un proceso de transformación específica del comportamiento humano. El concepto de civilité es expresión y símbolo de una formación social que abarca las más diversas nacionalidades y en que se habla de un lenguaje común.

Para logar el objetivo, se plantea un análisis hermenéutico de fuentes de diversos archivos históricos del Estado nacionales y departamentales. El artículo se desarrolla en dos capítulos: en el primero, se lleva a cabo un abordaje teórico sobre la colonización de frontera y el capitalismo, en el segundo, se estudia la colonización de frontera entre Colombia y Panamá.

\section{La colonización de frontera en los confines del capitalismo}

Las fronteras o bordes nacionales se piensan muchas veces como un ejercicio político en que se define la soberanía de un Estado nacional sobre el espacio geográfico, pero no se comprende muchas veces que tales espacios son fluidos y abiertos a intercambios de poblaciones de diversas nacionalidades en movimiento.

La historia de las "fronteras" nace mucho antes de las naciones: nace con la historia del capitalismo. Así, lo advierte Serge (2017), quien describe estos territorios como espacios dominados, espacios apropiados, espacios cambiantes, espacios de soberanías múltiples, espacios de ejercicio de poder, multiescalares (local-transnacional-mundial), espacios "otros", vacíos y dispuestos a la conquista, a la intervención, disponibles para ser explotados en la lógica del capitalismo. El capitalismo ha producido a lo largo de su historia formas específicas de territorialidad y de espacialidad. Desde una perspectiva histórica, es posible visualizar estas estrategias espaciales en la larga. 
Feldman-Bianco (2018) explica la territorialización a partir de prácticas de territorialidad en el espacio, tales como la delimitación, la clasificación, la habitación, el uso, la distribución, la defensa y la identificación. El espacio está principalmente dominado por la lógica contable de la economía de mercado.

El problema que se esboza en la historia de las fronteras nacionales es la de la transición de lo rural a lo urbano. Para remitirnos a dicha transición, Lefebvre (1978) sostenía:

Los problemas se superponen, se exasperan: destino de una tierra marcada por la historia, las tradiciones campesinas, los campesinos mismos. La industrialización se apodera de regiones hasta entonces olvidadas. La urbanización, cuya importancia crece sin cesar, transforma cuanto existía anteriormente. (p. 19)

La colonización de frontera es producto de un proceso civilizatorio donde la naturaleza salvaje es domesticada al servicio del mercado (Elias, 2012). La relación entre razón humana y naturaleza del espacio es siempre conflictiva, las fronteras territoriales son un abismo entre los procesos civilizatorios, la colonización y la nacionalización, en especial, en territorios donde una raza se siente superior a otra.

Verlinden (1970, citado en Appelbaum, 2007) señala que "la palabra colonización deriva del latín colere, que quiere decir cultivar o poner en uso y que inicialmente se refería a la expansión de los cultivos agrícolas" (p. 30). Para Parsons (1961), "el término más preciso en inglés para referirse a este proceso es el de settlements, asentamientos, que de manera más precisa abarca la dominación de una agreste zona" (p. 24).

Es preciso señalar que el concepto de colonización se nutre del concepto de producción del espacio acunado por Lefebvre (1974) en que el espacio producido socialmente genera espacialidad. Las representaciones en el espacio están todas conectadas a un modo de producción específico y son una expresión del capitalismo.

El proceso de colonialismo en América no terminó con la expulsión de los poderes coloniales europeos. El continuum colonial se perpetuó con el Estado independiente y el sometimiento de la población a las élites criollas que expandieron su poder hacia los confines de la nación se dio bajo lógicas de producción, acumulación y circulación de capitales. El Estado y su estructura interna, como la concentración de la tierra, sirvieron a los intereses del sector exportador y mantuvieron a algunas provincias y zonas de expansión de la frontera agrícola en absoluta pobreza (Kalmanovitz, 1984). 
La colonización es un proceso geográfico surgido a partir de flujos migratorios que producen un territorio, un asentamiento, incluso, una región. En Colombia, la colonización es producto del régimen agrario del siglo XIX, que se refiere a un sistema de haciendas que logra en gran medida monopolizar la tierra y someter un importante sector de la población a relaciones serviles de producción. Las trabas al desarrollo del capital están del lado de las relaciones sociales imperantes en el país que impiden una ocupación amplia y democrática de la tierra para extraer míseras rentas del campesinado (Kalmanovitz, 1984)

En Colombia, la geopolítica de la ocupación de los territorios de borde o de frontera en el siglo XIX se dio incentivando la migración europea.

\section{Según Kalmanovitz (1984):}

"A los nativos no se les titulaba ningún pedazo apreciable de tierra y hasta se les amenazaba con el desalojo. A los inmigrantes europeos se les ofrecían lotes de 300 y 600 fanegadas de extensión, mientras que las clases dominantes locales se apropiaban de miles de hectáreas" (p. 225).

Hablar de colonización en Colombia, por tanto, es referirse a la historia del poblamiento y de la apropiación de la tierra que responde a asuntos de clase y étnica. La colonización en el país respondió a intereses de los grandes terratenientes y de compañías extranjeras interesadas en el desarrollo de una industria agrícola.

La agricultura de subsistencia del siglo XIX mostró el dinamismo de la frontera en cuanto a producción, así, el paisaje natural fue modificado por la idea de "progreso" inducida por el capitalismo. El término progreso fue bastante utilizado por las clases dirigentes locales del siglo XIX. ${ }^{2}$ La idea de progreso se basó en la productividad ${ }^{3}$ del espacio geográfico: los territorios debían ser productivos y para ello era necesario la rentabilidad de la tierra, y así se percibió la naturaleza en América como factoría en tiempos de Revolución Industrial. El paisaje natural está siendo sometido a transformación por las manos del hombre. Mediante sus culturas, utiliza las formas naturales, en muchos casos las altera, y en algunos las

2 En el Fondo Gobierno Municipios del Archivo Histórico de Antioquia, los gobernantes de la provincia de Urabá se refieren al progreso como la capacidad del Estado para hacer productivo el espacio geográfico a través de obras públicas: explotación de la tierra.

3 La productividad es una medida económica que calcula cuántos bienes y servicios se han producido por cada factor utilizado (trabajador, capital, tiempo, tierra, etc.) durante un periodo determinado. Productividad $=$ Producción obtenida $/$ Cantidad de factor utilizado. 
destruye (Sauer, 2006). Lefebvre (1974) sostenía que el mundo de la mercancía, con su lógica y su lenguaje, se generaliza en lo cotidiano. Así pues, las fronteras nacionales no escaparon al mercado mundial que inspiró el imperialismo colonial del siglo XIX, conectó múltiples escalas geográficas (local, regional, nacional, supranacional) y desarrolló un sistema de producción orientado hacia la exportación (Hobsbawm, 2013).

Parsons (1950) define la región geográfica como una producción sociocultural en que el medio físico representa un papel importante mas no determinante. Tal y como lo consideraba teóricamente Sauer (2006), el paisaje cultural se superpone al paisaje natural, así, cultura es lo que posibilita la construcción del espacio social. Al relacionar la cultura regional con las condiciones geográficas e históricosociales, se refirió a los grupos indígenas primitivos y a la introducción de una economía agrícola cuyo máximo desarrollo se dio hacia fines del siglo XIX.

En los confines del Estado, el dominio territorial es líquido, siendo un continuum de soberanías en tensión política en que sus sociedades se relacionan desde lógicas de poder desarrolladas por los medios y las formas de producción del capital. El elemento de propiedad privada se impondrá al elemento colectivo de la sociedad rural (Marx y Engels, 1974).

La esencia de la producción social de las fronteras territoriales es la constante y permanente colonialidad del poder, concepto que fue propuesto por Quijano (2000) para referirse a la larga duración del colonialismo de Europa sobre América Latina. Uno de los ejes fundamentales de este proceso civilizatorio es la dominación de una clase social sobre otra determinada por la raza. No obstante, la sociedad criolla de Colombia le dio continuidad interna al colonialismo; la herencia colonial se mantuvo en la economía agraria del país a través de las élites criollas y de las provincias del país que pretendían apropiarse de la tierra, expandir la frontera agrícola allí donde antes las tierras habían sido agrestes. Las Provincias realizaron sus propias avanzadas de ocupación territorial para hacer de otras Provincias territorios productivos.

En América, el color de la piel se utilizó como símbolo que otorgaba legitimidad a las prácticas de explotación de unos sobre otros. La historia universal ha demostrado la dominación racial como el modus operandi del imperialismo para mantener relaciones de explotación en el capitalismo mundial. El colonialismo vio en el discurso sobre la raza la posibilidad de incursionar en territorios ajenos, 
poblar territorios de otras culturas, despojar a la población de sus creencias y generar procesos de aculturación y blanqueamiento. ${ }^{4}$

La palabra raza en Colombia está ligada tanto a la nación como a los componentes humanos y territoriales dentro de la nación. La raza se constituyó en un importante símbolo de identidad en la formación del Estado y la nación colombiana, y en la demarcación de fronteras entre las regiones del país (Appelbaum, 2007).

Hobsbawm (2013) señalaba el desarrollo del nacionalismo que establecía la clasificación entre el nosotros y los otros, de esta manera se crea la frontera que no solo es política, sino cultural y social.

Colombia ha sido una sociedad al servicio del capitalismo mundial. La historia del capitalismo mundial comprende una sucesión cronológica de formas y experiencias de dominación cultural. Este mundo se asienta bajo el signo de la desigualdad. Braudel (2002) sostenía: "El capitalismo es impensable sin la complicidad activa de la sociedad. Constituye forzosamente una realidad de orden social, una realidad de orden político, e incluso una realidad de civilización" (p. 37). Braudel (2002) afirma que en las zonas periféricas de la economía-mundo, donde podríamos señalar se sitúan los bordes nacionales, la vida de los hombres evoca a menudo el purgatorio, cuando no el infierno. El centro depende de los suministros de la periferia y esta, a su vez, de las necesidades del centro que le dicta su ley.

\section{La colonización de frontera colombo-panameña (1886-1941)}

La posición geográfica de Panamá, el Darién y el Atrato fueron de gran interés para la civilización occidental europea inspirados en el espacio vital que podría desarrollar su política exterior (Haushofer, 1927). Las expansiones de las fronteras territoriales se convirtieron en puntos de partida para preservar su civilización. El Estado no podía estar en una constitución de papel, sino que requería un plano físico.

En la psique colectiva de finales del siglo XIX y principios del siglo XX, habitaba un deseo de superioridad de la civilización europea, y el poder naval sería

4 Es una práctica social, política y económica utilizada en muchos países poscoloniales de América y Oceanía para "mejorar la raza" (Wade, 2000). 
la herramienta para hacer realidad su sueño. El mar era zona en disputa por los imperios europeos, escenario fantástico de la competencia por el poder mundial (Haushofer, 1927).

Existía, para la civilización europea, unos puntos geográficos que brindaban a los Estados ventajas comerciales y militares. Alfred Mahan en 1890 señalaba que el Caribe era para América lo que el Mediterráneo para Europa, analogía que tenía mayor sentido con la construcción del canal de Panamá. Lo anterior explica las posiciones agresivas que podrían tener los Estados europeos por la zona del canal en el Caribe, igualmente que, si se realizara el canal interoceánico en el Caribe, la situación de los Estados Unidos en relación con esta ruta sería análoga a la de Inglaterra respecto del canal de la Mancha o la que ocupaban las naciones mediterráneas en relación con el canal de Suez. El canal de Panamá debería obtener en el mar Caribe estaciones adecuadas para servir de base de operaciones accidentales o secundarias, que, por sus ventajas naturales, susceptibilidad de defensa y proximidad al paso estratégico central referido, facilitaría a sus escuadras permanencia cerca del teatro de guerra. El símbolo del poder naval de la civilización occidental era la creación de un canal interoceánico en el Caribe.

En la figura 1, se pueden observar las diversas rutas que se exploraron para el desarrollo de la obra arquitectónica de la civilización occidental europea, que tenía como propósito la circulación de mercancías para el comercio mundial. Durante la Constitución Política de 1863 Cauca, Bolívar, Panamá y Antioquia se disputaron el control del golfo del Darién donde está, en su parte más estrecha, el de Urabá. Los ejes Colón-Panamá, San Miguel-Caledonia, Punta Ardita-Cabo Tiburón y Atrato-Bojayá-Napipi fueron representaciones espaciales de la geografía estratégica para el comercio mundial.

La región de frontera tiene dos representaciones en la mentalidad del imperialismo del siglo XIX: a) frontera circular: fluida y abierta al mercado mundial, y b) frontera como borde o límite: una barrera cultural: espacio de la alteridad por motivos como etnia, religión y enfermedad. 
Figura 1. Mapa canalización y colonización del Atrato-Darién.

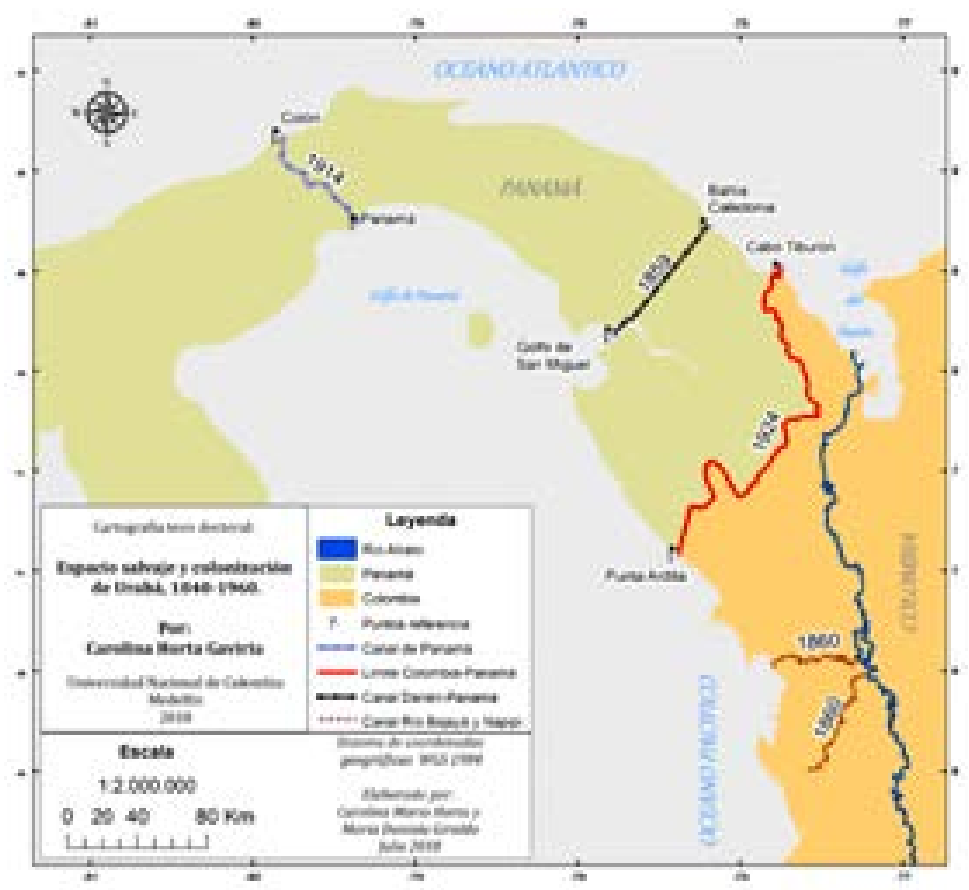

Fuente: elaboración propia a partir de varias propuestas y negociaciones celebradas por el Poder Ejecutivo de la Confederación Granadina y Estados Unidos de Colombia en París, Francia. AGNArchivo General de la Nación, Colombia. Fondo Canal Interoceánico. Carpeta 1, 2.

En 1880, Fernando de Lesseps inició las obras de un canal interoceánico con la Compagnie Universelle du Canal Interocéanique de Panama, que no progresaron (Du Boys, 1914). En 1894, aprovechando la situación, los norteamericanos con Theodore Roosevelt compraron la Compañía en quiebra, apoyaron la independencia de Panamá y desarrollaron el canal (Fisher, 1998).

La quiebra de la Compagnie Universelle du Canal Interocéanique de Panama se debió en gran parte a la fiebre delirante de los franceses producida por la malaria en el territorio migratorio Darién-Atrato-Panamá en el siglo XIX. ${ }^{5}$

5 El término malaria viene del vocablo italiano mal'aira que significa "mal aire". En América, los vientos miasmáticos también eran conocidos como malarias. Watts (1997) señala que en los primeros treinta años del siglo $X X$ se identificaron aproximadamente treinta tipos de Aedes aegypti. 
En 1910, los Estados Unidos lograron la ejecución del canal interoceánico gracias a los aportes del médico William Crawford Gorgas, quien informó cómo podía prevenirse la malaria en el istmo de Panamá mediante el control del mosquito Anopheles, que la causaba a trabajadores, marinos y personal del canal. El doctor evidenció que la malaria se presentaba en especial durante junio, julio y agosto, épocas de lluvia. Otra variable que encontró Gorgas fue el contacto de la tripulación europea y luego norteamericana con los otros, los nativos de aquella zona (Gorgas, 1910).

En la zona del canal de Panamá, los trabajadores se encontraban con la muerte, hasta que, mediante estrategias profilácticas y el empleo de la quinina, se controló la malaria entre 1906 y 1909. Solo por medicalización del espacio la zona dejó de ser una frontera para el capitalismo global. Pero este espacio Atrato-Darién-Panamá continuó siendo una frontera cultural para la civilización occidental, que veía en los otros a seres enfermizos con quienes debía evitar el contacto para reducir el contagio.

Los otros fueron identificados con los estigmas de la raza y, sobre todo, de la enfermedad. Según Goffman (1970), los estigmas son huellas o marcas que hacen del otro alguien a quien se puede señalar. La percepción de los europeos sobre los otros en la zona del canal partió de asumir que había algo enfermizo en su naturaleza individual, colectiva y territorial. La civilización norteamericana con sus técnicas del siglo XIX se impuso sobre la zona del canal interoceánico, borró la historia de la nación panameña y produjo la zona del canal de Panamá sin panameños. (Lasso, 2019)

Los norteamericanos en 1903 llegaron a una zona llena de gentes, cultivos y negocios con una larga historia política y municipal. Pero la historia de la zona del canal de Panamá fue borrada por los estadounidenses quienes despoblaron el espacio por motivos raciales. (Lasso, 2019)

$\mathrm{Al}$ otro lado, en Colombia, pasaba una historia similar, se pretendía borrar la raza en lo que podría ser una colonia europea: Urabá. Después de la separación de Panamá, en 1903, el golfo del Darién se fragmentó en dos partes: una en Panamá y otra en Colombia; la zona de dominio colombiana se empezó a nombrar como golfo de Urabá a partir de la ley 17 de 1905 que le otorgó soberanía a Antioquia sobre la Provincia del Atrato, cumpliendo la función de frontera con Panamá y fuerte militar con los Estados Unidos. 
Como frontera internacional, Urabá posee una importancia geográfica estratégica de interés público mundial, pues este territorio está situado entre dos océanos: Atlántico y Pacífico; además, domina un corredor estratégico fluvial: el río Atrato, que conecta el mundo oceánico con el interior de América del Sur. Por su parte, el golfo del Darién es una zona del mar Caribe utilizada por imperios de todos los tiempos para comunicar el norte con el sur del continente americano.

La región del Atrato (Chocó) se constituyó en la frontera colombiana. Sostiene Steiner (2000) que su identidad se erigía orgullosamente en contra del "vecino traidor". Steiner cita el diario Ecos Republicanos, publicado en Quibdó: "El Chocó reemplaza a Panamá en todo sentido, menos en que jamás será traidor a la patria” (p. 9).

La estrategia del Estado fue promover la colonización europea previendo una posible intervención militar de los Estados Unidos en otro territorio de Colombia. Colombia no reconocía la separación de Panamá y se refería a ella como un protectorado norteamericano. ${ }^{6}$ Los dirigentes del país creían que, estimulando la colonización europea, en especial la belga-alemana, podrían incentivar el progreso material del país. Ya en el siglo XVIII existía antecedentes de la colonización alemana, pues llegó una colonia de ocho mineros alemanes, que ayudaron a mejorar la técnica de extracción de metales. Después de la independencia, dos de ellos, Jacobo Wiesner y Friedrich Bayer, permanecieron en la Nueva Granada (Melo, 2020, p. 335).

Como sostiene Melo (2020): "Los gobiernos buscaban ante todo promover la economía, pero además 'mejorar' la población trayendo grupos humanos como la 'vigorosa e inteligente raza europea', según la llamó Manuel Ancizar en 1847" (p. 336).

La colonización alemana se estimuló en la Regeneración mediante el desarrollo de la producción y exportación de frutas tropicales como el banano, también para la explotación minera y de maderas.

El Estado republicano entregó baldíos a municipios, regiones y provincias para que fueran adjudicados a pobladores nacionales y extranjeros dispuestos a cultivar tierras de la nación. (Tovar, 2015)

6 Soberanía parcial que un Estado ejerce sobre un territorio que no está incorporado por completo a esa nación y que posee autoridades propias. 
La República conservadora para el periodo 1886-1930 le dio gran importancia a la empresa rural basada en el progreso técnico y al desarrollo de nuevas formas de actividad productiva que impulsara nuevos cultivos. Asimismo, la apertura de haciendas y el desarrollo de vías de comunicación para impulsar el comercio (Melo, 2020).

La frontera con Panamá en el Urabá se desarrolló a partir del estímulo a la colonización alemana como estrategia patriótica basada en la idea de una "mejor civilización”. Panamá y la Provincia del Atrato de dominio antioqueño conocida como Urabá fueron territorios imaginados como enclaves para las relaciones de economía-mundo, mediante un sistema de canalización interoceánica, desarrollo de puertos y ferrocarriles y explotación industrial agrícola del suelo.

El Gobierno colombiano envió varios comunicados diplomáticos y creó la Ley 66 de 1909 para estimular el desarrollo de una colonia agrícola alemana y belga en la frontera entre Colombia y Panamá. Henry Dannenfeldt (1909) de Hamburgo solicitó 900 hectáreas para el cultivo de banano al Ministerio de Obras públicas. También a Oscar Egersdofer se le titularan 4997 hectáreas para el cultivo de banano (Steiner, 2000, p. 24). El Gobierno colombiano les encomendó a los alemanes a cambio de la colonia agrícola en el Urabá la realización de un muelle, una línea telegráfica y algunas prácticas sanitarias en el espacio territorial (Dannenfeldt, 1909).

Gómez (1913), citado en Steiner (2000), señala:

El grande y contante empuje que la compañía del Consorcio ha dado a sus propiedades ha transformado aquellas salvajes y pantanosas playas, antiguo albergue de la desolación y de la muerte, en un emporio de riqueza, de industria y de trabajo, que predicen los gérmenes de un futuro e importante centro avanzado al norte de nuestra nacionalidad... La localidad se ha saneado hasta donde lo ha permitido las circunstancias del terreno y del clima, y los inconvenientes y hostilidades de los naturales de la región. (p. 25)

Las élites nacionales de la Regeneración querían una nación "civilizada" a imagen y semejanza de Europa, para ello era necesario "blanquear" a la sociedad colombiana, tal y como lo indicaba el discurso eugenésico. ${ }^{7}$

7 Según el Diccionario de la lengua española, la eugenesia es el "estudio y aplicación de las leyes biológicas de la herencia orientados al perfeccionamiento de la especie humana" (Real Academia Española [RAE], 2014). 
Wade (2000):

\begin{abstract}
A finales del siglo XIX y principios del XX tuvo éxito el racismo científico que clasificó a las razas, los tipos raciales se ordenaron jerárquicamente, justificando la inferioridad racial y el dominio sobre los negros, viéndolos como inferiores. Esta teoría tuvo lugar después de que se había logrado abolir en gran medida el comercio de esclavos y la esclavitud después. En el siglo XIX el utilitarismo se volvió central y aunque el concepto de raza no debería invocarse directamente, los principios de utilidad y bien colectivo permitieron el autoritarismo, donde los más racionales (los colonizadores blancos) decidieron en base a fundamentos raciales lo que era mejor para los menos racionales (los negros colonizados). Así fue como John Stuart Mill, el gran exponente del utilitarismo, pregonaba la necesidad de gobernar a las categorías inferiores menos civilizadas. (p. 18)
\end{abstract}

A comienzos del siglo XX, la Sociedad de Estudios Franco-Belga se dedicó en especial a la actividad de explotación maderera (Olaya, 1910). Los nombres más reconocidos de esa empresa fueron Oscar Egersdorfer, Henry Hechtel y V. Kashler (Keep, 1910).

El Ministro de Obras Públicas expresó la importancia de interesar elementos alemanes en el territorio del Urabá para penetración patriótica (Jiménez, 1907). Así que la raza era el adjetivo de la patria en el discurso político constitucional de los primeros años del siglo XX. El 21 de diciembre de 1909, Hermann Span (1912), vecino de Reutlingen, del Imperio alemán, envió un comunicado al Ministerio de Obras Públicas en el que pedía 900 hectáreas para realizar varios cultivos y explotación de maderas.

Mientras se enviaban los comunicados diplomáticos que estimulaban la migración alemana para colonización en territorios de Colombia, Alemania vivía el segundo Reich (1871-1918). Tras su unificación tardía en 1871, al finalizar la guerra contra Francia, Alemania buscaba ser una potencia continental a la zaga del reparto del mundo entre las potencias imperiales industriales (De Napoli, 2016).

El cultivo del banano fue desarrollado por el consorcio alemán Albingia, por Ley 66 de 1909, en que se aprueba el contrato con el Gobierno Nacional. El consorcio Albingia logró ese año titular 4997 hectáreas de tierras baldías para el cultivo de banano tipo exportación. La obra comprendía, además, el desarrollo de un ferrocarril entre Turbo y el río León. El representante legal de la compañía era un alemán: Oscar Egersdorfer, quien contrató con el Estado colombiano la concesión de explotación del suelo por cincuenta años. 
Jose María Uribe Ospina (1912), prefecto de Urabá, afirmaba que la empresa alemana Albingia tenía el monopolio de una zona comprendida entre el río León y la serranía de Abibe. El privilegio obtenido por ley prohibía cualquier otro muelle, en una extensión de tres leguas a lado y lado de Puerto Cesar, asiento de los trabajos alemanes.

En 1912, los alemanes pensaban desarrollar una colonia con auspicio del Gobierno de Colombia. Según la Junta de Emigración Wisher, dirigida por Richard Wisher, varias familias alemanas estaban interesadas en fundar una colonia, de extensión por lo menos de 25000 hectáreas, más unas 15000 a su alrededor para suplir a los colonos que fueran llegando. Deseaban que fuera en territorio sano, cerca de vías de comunicación y adecuadas para su fundación. La sociedad de colonos alemanes contaba con cerca de cien familias en buenas condiciones y aptas en varios oficios, principalmente, agropecuarios y mercantiles. La zona que explotaron se extendió desde el río León hasta la serranía de Abibe.

No obstante, como dice Ana Milena Rhenals Doria (2013) en la región del río Atrato, frontera entre Panamá y Colombia se pasó del ideal europeo a la realidad árabe. En el circuito comercial entre Cartagena, el Sinú y el Atrato el Gobierno colombiano contó con la presencia sirio-libanesa.

Indica Rhenals (2013):

A finales del siglo XIX, grupos de sirios y libaneses salieron de sus tierras huyendo del poder de Turquía que para esta época hizo sentir su peso en dichos países. Como producto de la matanza de cristianos ejecutada por los drusos y estimulada por los otomanos, miles de sirio-libaneses de Damasco, Beirut, Zahale, Malula, Baabda, en su mayoría cristianos maronitas, emigraron en busca de un horizonte más seguro y de mejores posibilidades económicas. (p. 56)

Enrique Olaya Herrera (1910), ministro de Relaciones Exteriores, denunció que el eje del Atrato se estaba convirtiendo en una colonia extranjera. Las ciudades del Caribe colombiano fueron las principales receptoras de inmigrantes sirio-libaneses, quienes dinamizaron el comercio. La ruta del Atrato les atrajo para desarrollar el comercio, la producción agrícola y la explotación de oro.

8 En Colombia, residían 3767 individuos de origen sirio-libanés. Algunos investigadores van más allá y hablan de un número entre los 3000 y los 10000 en el periodo 1880-1930 (Memorias del I Encuentro Cultural Colombo-Árabe, 2005, citado en Rhenals, 2013). 
En la frontera entre Colombia y Panamá, región Atrato, fue célebre Nazir Tobías Yabur, quien fue naturalizado por el ministro de Relaciones Exteriores de la época, Enrique Olaya Herrera (1911). Los baldíos adquiridos por Nazir Tobías Yabur se encontraban en Puerto Cesar y en el río León, suelos fértiles, apetecidos para la extracción de maderas (Bravo,1910).

En 1913, el prefecto de Urabá, Ricardo Zuluaga, informó que la empresa alemana Hamburg Columbien Bananen, consorcio Albingia, había abandonado sus terrenos en La Patria y Puerto Cesar. Después de la Primera Guerra Mundial, hubo tensión entre el Gobierno de los Estados Unidos y el de la República de Colombia por albergar esta empresa alemana (Ariza, 2012).

Afirma Steiner (2000):

Cuando estalló la Primera Guerra Mundial todas las expectativas de la Hamburg Columbien Bananen se desmoronaron, los socios del consorcio abandonaron la región dejando vías férreas sin terminar, plantaciones recién sembradas y un muelle inconcluso, de este muelle o "warfe" quedaría el nombre wafe.' (p. 26)

En 1915, el sirio-libanés Nazir Tobías Yabur solicitó al departamento de Antioquia las tierras abandonadas por la empresa alemana Hamburg Colombien Bananen, para dedicarlas a pastos de ganadería, plantaciones agrícolas y explotación de maderas. Según escritura pública n. ${ }^{\circ} 13$ de 11 de mayo de 1919, Notaría del Circuito de Urabá, en 1919, el señor Elias Eljach, de nacionalidad alemana, le vendió las tierras de esta compañía a Nazir Tobías Yabur, una de ellas denominada Plaza de la Marimonda (Gonzáles, 1922). Según la Gobernación de Antioquia, la Marimonda estaba situada en Playa Marimonda, en el corregimiento de Necoclí (Marulanda,1922). Según la Secretaría de Hacienda de Antioquia, el señor Nazir Tobías Yabur se dedicaba a la exportación de tagua y cedro en las riberas del río León y del río Atrato.

Para 1917, el Atrato era la zona exportadora de platino más importante del mundo debido a la fuerte demanda europea (Rhenals, 2013). Los recursos mineros del Atrato fueron explotados por compañías belgas, francesas y estadounidenses como The Quibdo Gold Dredging Co, Certegui Mining \& Dredging Co, The Colombian Goldfield Co, British Platinum \& Gold Corp, Compañía Minera del Pacífico, y pequeñas y medianas empresas de inmigrantes y nacionales (Diario de

9 Todavía hoy los habitantes de Turbo llaman al embarcadero Wafe. 
la Costa, 1917 citado en Rhenals, 2013, p. 52). No obstante, algunos propietarios del litoral Pacífico (1910) escribieron una carta en que denunciaban que la explotación del oro no se convertía en capital humano, en servicios de salud o de infraestructura en Urabá.

Al respecto, en 1920, se expidió la Ley 48 sobre inmigración y extranjería, en cuyo espíritu y letra se halla la tendencia a imponer normas restrictivas a la inmigración. Posteriormente, la Ley 114 de 1922 sobre inmigración y colonias agrícolas prohibió la entrada al país de población que por sus condiciones étnicas, orgánicas o sociales fueran un inconveniente para la nacionalidad.

Según Rhenals (2013), existía un carácter selectivo del Estado en materia migratoria. Se consideraban razas superiores a germanos, franceses, españoles, italianos y suizos, e inferiores a eslavos, armenios, sirios, libaneses y chinos (p. 45). La realidad inmigratoria de Colombia, carente de flujos europeos significativos, estaría marcada precisamente por la presencia de los inmigrantes catalogados como indeseables e inferiores en Urabá.

En 1920, la Asamblea firmó la Ordenanza n.o 68 de 1920 que se tituló "So-bre colonización de tierras departamentales y fomento de las industrias", y se relacionó un informe de las adjudicaciones de baldíos en la región del río León (1925), que continuaban entregando tierras a los extranjeros para que adelan-taran procesos industriales y a la Compañía Agraria del Caribe. Emilio Bahoy (28.12.1919-31.5.1920) solicitó 2000 hectáreas al Ministerio de Obras Públicas para una colonia de cerca de cien familias de emigrantes alemanes.

El proyecto de colonización requería navegación aérea para el desarrollo de negocios en la región. El prefecto civil de Urabá, Eusebio Campillo, solicitó en 1931 la realización de la escala de los aviones de la Sociedad Colombo-Alemana de Transportes Aéreos (Scadta) en Turbo. Gonzalo Mejía logró crear el servicio de navegación aérea entre Medellín y el golfo de Urabá (Ley 8 de 1931).

La presencia alemana a través de Scadta se hizo notable en 1932 debido al conflicto fronterizo amazónico protagonizado por Perú y Colombia. La causa fue el control de las reservas de caucho y petróleo. El Estado colombiano requería una fuerza área adecuada y para ello contrató a los alemanes en Scadta (1919-1939)..$^{10}$ Este conflicto involucró también a militares norteamericanos,

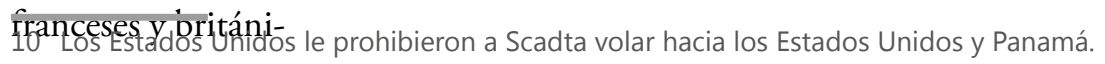


cos que conocieron la participación de pilotos y aviones de guerra alemanes. Los Estados Unidos contuvieron la colonización alemana en Colombia y, en general, la colonización europea amparados en la doctrina Monroe. ${ }^{11}$

Por tal motivo, en 1933, se prohibió a Scadta volar hacia los Estados Unidos y Panamá durante el Gobierno de Herbert Clark Hoover (1929-1933), porque la presencia alemana era una amenaza al espacio vital de los Estados Unidos.

La casa alemana Siemens Baunion en 1935 proyectó a Necoclí como futuro puerto de Urabá y propuso una colonia penal para la explotación agrícola de la región. En 1935, Gonzalo Mejía (1939) emitió un comunicado a la Gobernación para desarrollar una colonia penal en la empresa Agrominera de Urabá S. A. entre los ríos Mutatá y el Tasidó. La empresa construiría los campamentos que se necesitaran para la concentración de presos, oficinas de empleados y servicios para el mantenimiento de la colonia penal. La compañía facilitaría las máquinas agrícolas e industriales para sembrar árboles de cacao. Los presos debían dedicarse a la siembra de árboles de cacao y prestarían servicios de seguridad con sus empleados a esta colonia.

Con el tránsito en Alemania de la República de Weimar (1918-1933) a la Alemania nazi (1933-1945), en 1937, los nazis comenzaron a infiltrarse en el grupo de pilotos de Scadta. La empresa seleccionaba su personal en Alemania, la mayoría graduados de la Escuela Gubernamental de Pilotos de Transporte Alemán (Bosemberg, 2015). En Colombia, también se hacía una transición de la Regeneración y la Hegemonía Conservadora a la Hegemonía Liberal, lo cual significaba que habría lugar a cambios en las relaciones diplomáticas de Alemania a los Estados Unidos. El 23 de julio de 1940, Colombia retira al personal alemán de Scadta como muestra de buenas prácticas diplomáticas con los Estados Unidos que intervino en la guerra europea en 1941. A la mañana siguiente, Scadta comenzó a funcionar con la administración de los equipos de Pan American (Roca, 1940). Colombia mantuvo vigilancia sobre los inmigrantes alemanes y abandonó la empresa colonizadora alemana en las costas y en Bogotá.

11 La doctrina Monroe consistía en considerar cualquier intervención europea en los destinos de los países americanos como un agravio directo a los Estados Unidos, lo que ameritaría una respuesta inmediata y contundente. 


\section{Conclusiones}

En el proceso de formación de un enclave agrícola del sistema capitalista en la frontera entre Colombia y Panamá 1886-1930. Después de la separación de Panamá fue importante la promoción de la colonización alemana la que se vio afectada por La Primera y Segunda Guerra Mundial, por lo que los terrenos de sus compañías agrícolas fueron abandonados. Pese a que la migración árabe no era deseable en el país, en Urabá, en la región del Caribe y en la región del Atrato (Chocó), zona de frontera entre Colombia y Panamá, se les titularon baldíos, que fueron de propiedad alemana, en este aspecto, se conoce bastante bien la colonización en Urabá del sirio-libanés Nazir Tobías Yabur a quien se le titularon en un alto porcentaje algunos terrenos de las compañías alemanas. La colonización sirio-libanesa en la zona se dedicó a la explotación aurífera y de maderas (tagua y cedro), materias primas necesarias para la exportación hacia Europa. (Gonzales, 1922).

La colonización alemana en Urabá fue promovida por el Gobierno colombiano de la Regeneración y por la Hegemonía Conservadora; en este sentido, se enviaban distintas comunicaciones diplomáticas que ofertaban las ventajas de localización geográfica de Urabá para el comercio exterior y la producción agrícola en un contexto de competencia imperial. El proceso de "blanqueamiento" de la población era la promesa alemana para la "evolución cultural" deseada por el Estado colombiano y sus élites regionales y nacionales. Económicamente, la industria y el mercado de banano (tipo exportación) fue estimulado, en especial, por alemanes.

Entre 1931 y 1935, la navegación aérea también fue importante gracias a los aportes de los alemanes representados en Scadta (1919-1940); también el desarrollo de un puerto en Urabá fue promovido por los alemanes. No obstante, los Estados Unidos bloquearon la migración colonial alemana en Urabá basándose en la doctrina Monroe y en la seguridad colectiva proclamada en la Segunda Guerra Mundial. La Hegemonía Liberal fue lo suficientemente obediente para acceder a las disposiciones del imperio norteamericano.

\section{Referencias}

Appelbaum, N. (2007). Dos plazas: una nación: raza y colonización en Riosucio, Caldas, 1846-1948. Instituto Colombiano de Antropología e Historia.

Ariza Cárdenas, V. C. (2012). El movimiento campesino en el Urabá Antioqueño: una aproximación al problema agrario (1960-2000) (Tesis de pregrado, Universidad Javeriana). https://repository.javeriana.edu.co/bitstream/handle/10554/14318/ArizaCardenasVivianaCamila2012.pdf?sequence $=1$ \&isAllowed $=y$ 
Asamblea Nacional Constituyente y Legislativa de Colombia. (1905, 15 de abril). Ley 17. Sobre división territorial. Diario Oficial 12328. http://www.suin-juriscol.gov.co/ viewDocument.asp?ruta $=$ Leyes $/ 1572890$

Bahoy, E. (1919). Carta de Emilio Bahoy al Ministro de Obras Públicas. Honduras, 19191920. Fondo: Fomento Baldíos, Tomos 46, ff. 440r, 442r, y 47, f. 58r.

Betancur, A. (1935). Solicitud fundación de una colonia penal agrícola en las costas del golfo de Urabá, Turbo. Fondo: Gobierno Municipios, Tomo 450, f. 261r.

Bosemberg, L. E. (2015). La Alemania nacionalsocialista, la Scadta y la aviación colombiana en la década de 1930. Universidad de los Andes.

Braudel, F. (2002). La dinámica del capitalismo. Fondo de Cultura Económica.

Bravo, A. (1910). Expedientes de baldíos tomado por Nazir Tobías Yabur enviado por el Concejo Municipal de Turbo al Sr. Ministro de Obras públicas. AGN-Archivo General de la Nación, Colombia. Fondo: Fomento Baldíos. Tomo 34, f. 68r.

Colmenares, G. (1989). Relaciones e Informes de los Gobernantes de Nueva Granada. Fondo de Promoción de la Cultura del Banco Popular.

Congreso de Colombia. (1909, 14 de diciembre). Ley 66. Que aprueba, con modificaciones un contrato celebrado por el Gobierno Nacional. Diario Oficial 13865. http:// www.suin-juriscol.gov.co/viewDocument.asp?ruta=Leyes/1617363

Congreso de Colombia. (1920, 3 de noviembre). Ley 48. Sobre inmigración y extranjería. Diario Oficial 17392. http://www.suin-juriscol.gov.co/viewDocument. asp?id $=1602224$

Congreso de Colombia. (1922, 30 de diciembre). Ley 48. Sobre inmigración y colonias agrícolas. Diario Oficial 18693. http://www.suinjuriscol.gov.co/viewDocument. asp?id $=1602224$

Congreso de Colombia. (1931, 14 de enero). Ley 8. Por la cual se aprueba un contrato (el celebrado con Gonzalo Mejía sobre establecimiento de un servicio de navegación área entre Medellín y el golfo de Urabá), y se dan algunas autorizaciones al Gobierno. Diario Oficial 21596. http://www.suin-juriscol.gov.co/viewDocument. asp?ruta $=$ Leyes $/ 1563410$

Constitución Política 1832 (marzo 1) Constitución Política del Estado de Nueva Granada de 1832. http://www.suin-juriscol.gov.co/clp/contenidos.dll/Constitucion/30020217

Constitución Política 1863 (mayo 8).

https://www.suin-juriscol.gov.co/viewDocument.asp?id=30020080

Constitución Política de 1886 (agosto 5).

http://www.suin-juriscol.gov.co/viewDocument.asp?id=1826862

Dannenfeldt, H. (1909). Carta al Sr. Ministro De Obras Públicas solicitando algunas hectáreas en Urabá para colonización. AGN-Archivo General de la Nación, Colombia. Fondo Baldíos. Tomo 43, f 629r.

De Lesseps, F. (1884). Informes sobre el ferrocarril y canal de Panamá. Imprenta de Vapor de Zalamea Hermanos.

De Napoli, C. (2016). Nazis en el sur. Ediciones B.

De Puydt, L. (1864). Canal del Darién y manuscrito dedicado al General Mosquera, titulado "El istmo americano". AGN-Archivo General de la Nación, Colombia. Fondo Canal Interoceánico. Carpeta 2. Legajo 3.

De Puydt, L. (1865). Propuesta de Luciano de Puydt al Senado plenipotenciario. AGNArchivo General de la Nación, Colombia. Fondo Canal Interoceánico. Carpeta 2. Legajo 4. 
Departamento de Antioquia. (1915). Juzgado del circuito de Urabá. Comunicación al Ministerio de Obras Públicas. Embargo preventivo de los bienes de la Compañía denominada Hamburg Colombien Bananen A. G. AGN-Archivo General de la Nación, Colombia. Fondo: Fomento Baldíos. Tomo 38, ff. 217r, 218r.

Du Boys, J. T. (1914). Colombia's claims and rights: Pennsylvania, Congressional record. The proceedings and debate of the sixty-thirds congress (2. ${ }^{a}$ ed.). United States Government Publishing Office.

Elias, N. (2012). El proceso de la civilización: investigaciones sociogenéticas y psicogenéticas. Fondo de Cultura Económica.

Feldman-Bianco, B. (2018). Anthropology and ethnography: The transnational perspective on migration and beyond. Etnográfica: Revista do Centro em Rede de Investigação em Antropologia, 22(1), 195-215. https://doi.org/10.4000/etnografica.5203

Fischer, T. (1998). Antes de la separación de Panamá: la guerra de los Mil Días, el contexto internacional y el canal. Anuario Colombiano de Historia Social y de la Cultura, 25, 73-108. https://revistas.unal.edu.co/index.php/achsc/article/view/16676

Garcés, A. (1910). Comunicación al Ministerio de Obras Públicas sobre denuncias de despojo a propietarios del litoral Pacífico. Fondo: Fomento Baldíos. Tomo 34. FF $213 r, 214 r, 215 r, 216 r$.

Gobernación de Antioquia, Secretaría de Hacienda. (1922). Comunicación al Ministerio de Agricultura y Comercio. AGN-Archivo General de la Nación, Colombia. Fondo: Fomento Baldíos. Tomo 50, ff. 204r, 205r, 207r.

Goffman, E. (1970). Estigma: la identidad deteriorada. Amorrortu.

Gonzales, L. (1922). Venta de propiedad de Elias Eljach a al Sr. Nazir T. Yabur. Notaria del circuito de Urabá. AGN-Archivo General de la Nación, Colombia. Fondo: Fomento Baldíos. Tomo 50, ff. 211r, 211v, 212r, 212v, 213r, 213v.

Gorgas, W. (1910). Malaria prevention on the Isthmus of Panama. En R. Ross, The prevention of malaria. E. P. Dutton \& Co, 1910. https://archive.org/details/prO0eventionofmalarossrich/page/366

Gorgas, W. C. (1915). Sanitation in Panama. D. Appleton.

Haushofer, K. (1927). Greographische Grundzüge auswärtige Politik. Süddeutsche Monatshefte, 9, 258-261.

Hobsbawm, E. (2013). La era del imperio, 1875-1914. Crítica.

Jiménez, D. (1907). Carta al Ministerio de Obras Públicas solicitando penetración patriótica alemana. Fondo: Fomento Baldíos. Tomo 32, f. 447r.

Kalmanovitz, S. (1984). El régimen agrario durante el siglo XIX en Colombia. En Manual de historia de Colombia (t. II). Instituto Colombiano de Cultura.

Keep, F. (1910). Monografía de Urabá. Imprenta Departamental de Antioquia.

Lasso, M. (2019). Erased: The Untold Story of the Panama Canal. Harvard University Press.

Lefebvre, H. (1978). De lo rural a lo urbano. Península.

Martín, F. (1859). Negociaciones seguidas en París por el S[eño]r de Francisco Martin, autorizado por el P[oder] E[jecutivo] de la Confederación Granadina. AGN-Archivo General de la Nación, Colombia. Fondo Canal Interoceánico. Carpeta 2. Legajo 1.

Marulanda, J. M. (1922). Secretaría de Hacienda. Gobernación de Antioquia. Comunicaciones al Ministro de Agricultura. AGN-Archivo General de la Nación, Colombia. Tomo 50, ff. 208r.

Marx, K. y Engels, F. (1974). Obras escogidas (t. 2). Progreso. 
Mejía, G. (1939). Documento de Gonzalo Mejía, Agrominera de Urabá S. A. sobre el traslado de la colonia penal de Antadó a Necoclí en el golfo de Urabá. C-AHA Archivo Histórico de Antioquia. Fondo: Fomento Gobierno municipios, Tomo 467, f. $322 r, 324 r$.

Melo González, J. O. (2020). Colombia: una historia mínima. Crítica.

Olaya Herrera, E. (21 de marzo de 1911). Expedición de carta de naturaleza del Sr. Nazir Tobias Yabur. AGN-Archivo General de la Nación, Colombia. Sección: República. Fondo: Fomento Baldíos, Tomo 35, f. 385r.

Olaya Herrera, E. (7 de noviembre de 1910). Carta de Enrique Olaya Herrera al Ministerio de Obras Públicas. AGN-Archivo General de la Nación, Colombia. Sección: República. Fondo: Fomento Baldíos, Tomo 34, f. 87r.

Parsons, J. J. (1950). La colonización antioqueña en el occidente de Colombia. Imprenta Departamental de Antioquia.

Parsons, J. J. (1967). Antioquia's corridor to the sea: An historical geography of the settlement of Urabá. University of California Press.

Paz, A. (1909). Expediente sobre baldíos tomados por Nazir Tobías Yabur enviado por el Consejo Municipal de Turbo. AGN-Archivo General de la Nación, Colombia. Fondo: Fomento Baldíos. Tomo 32, ff. 87r.

Prefectura de la Provincia Turbo. (1925). Esquema de las adjudicaciones de baldíos en la región del Río León. AGN-Archivo General de la Nación, Colombia. Tomo 63, f. 138r.

Puydt, L. (1864). Negociaciones sobre un canal interoceánico en el Darién. Manuscrito dedicado al General Mosquera, titulado "El istmo americano". AGN-Archivo General de la Nación, Colombia. Fondo Canal Interoceánico. Carpeta 2. Legajo 3.

Quijano, A. (2000). Colonialidad del poder, eurocentrismo y América Latina. En E. Lander (comp.), La colonialidad del saber: eurocentrismo y ciencias sociales. Perspectivas latinoamericanas. (pp. 201-246). Consejo Latinoamericano de Ciencias Sociales. https:// www.decolonialtranslation.com/espanol/quijano-colonialidad-del-poder.pdf

Real Academia Española. (2014). Eugenesia. En Diccionario de la lengua española. (23. ${ }^{a}$ ed.). https://dle.rae.es/eugenesia

Rhenals Doria, A. M. (2013). Del ideal europeo a la realidad árabe: inmigrantes siriolibaneses en el circuito comercial entre Cartagena, el Sinú y el Atrato (Colombia), 1880-1930 (Tesis de doctorado, Universidad Pablo de Olavide). https://rio.upo.es/ xmlui/handle/10433/1971

Roca Castellanos, M. (1940). Informe de los empleados alemanes despedidos de Scadta. Scadta. https://scadta.co/1940-empleados-alemanes-de-scadta/

Sauer, C. O. (2006). La morfología del paisaje. Polis: Revista Latinoamericana, 15. https:// journals.openedition.org/polis/5015

Serje, M. (2017). Fronteras y periferias en la historia del capitalismo: el caso de América Latina. Revista de Geografía Norte Grande, 66, 33-48. http://dx.doi.org/10.4067/ S0718-34022017000100003

Steiner, C. (2000). Imaginación y poder: el encuentro del interior con la costa en Urabá, 1900-1960. Universidad de Antioquia.

Tilly, C. (1991). Coerción, capital y los Estados europeos 990-1990. Alianza Editorial.

Jose María Uribe Ospina (1912). Informe de la Prefectura de Urabá. AHA-Archivo Histórico de Antioquia. Fondo Gobierno Municipios. Tomo 244, ff. 286r, 289r, 290r.

Wade, P. (2000). Raza y etnicidad en Latinoamérica. Abya Yala.

Watts, S. (1997). Epidemics and history: Disease, power and imperialism. Yale University. 